\title{
Radiosensitization of Clioquinol Combined with Zinc in the Nasopharyngeal Cancer Stem-like Cells by Inhibiting Autophagy in Vitro and in Vivo
}

\author{
Yuan $\mathrm{Ke}^{1,2^{*}}$, Chaoyan $\mathrm{Wu}^{3 *}$, Yifei Zeng1,2, Mengge Chen ${ }^{1,2}$, Yonghong $\mathrm{Li}^{1,2}$, Conghua Xie ${ }^{1,2}$, Yunfeng \\ Zhou ${ }^{1,2}$, Yahua Zhong ${ }^{1,2}$, Haijun Yu ${ }^{1,2}$ \\ 1. Department of Radiation and Medical Oncology, Zhongnan Hospital of Wuhan University, Wuhan, China \\ 2. Hubei Key Laboratory of Tumor Biological Behaviors, Wuhan, China; Hubei Cancer Clinical Study Center, Zhongnan Hospital of Wuhan University, \\ Wuhan, China \\ 3. Department of Integrated Traditional Chinese Medicine and Western medicine, Zhongnan Hospital of Wuhan University, Wuhan, China \\ * These authors contributed equally to this work. \\ $\square$ Corresponding author: Haijun Yu, Department of Radiation and Medical Oncology, Zhongnan Hospital of Wuhan University, Wuhan, China, 169 Donghu \\ Road, Wuhan, China,430071. E-mail: haijunyu@whu.edu.cn \\ (1) The author(s). This is an open access article distributed under the terms of the Creative Commons Attribution License (https://creativecommons.org/licenses/by/4.0/). \\ See http://ivyspring.com/terms for full terms and conditions.
}

Received: 2019.09.15; Accepted: 2019.11.12; Published: 2020.01.14

\begin{abstract}
Loco-regional recurrence of nasopharyngeal carcinoma (NPC) after radiation therapy is one of the main types of treatment failure. This study is aimed to explore the possible causes of inside-field recurrence of NPC patients in order to develop effective treatment methods. Our study indicated that CD44 and autophagy proteins in tumor tissues of patients with recurrent NPC are higher than that of the relapse free patients. The in vitro experiments further confirmed that cancer stem cells (CSCs) were more radioresistant with enhanced autophagy activity. Treatment with clioquinol (CQ) combined with zinc could obviously enhance the radiosensitivity of CNE-2s cells through autophagy inhibition, activation of the caspase system and impairment of DNA damage repair. The in vivo experiments have further consolidated our findings. Our results suggest that CSCs and enhanced autophagy activity may be involved in the inside-field recurrence of NPC, and CQ combined with zinc could be an important therapeutic approach for recurrent NPC.
\end{abstract}

\section{Introduction}

Radiotherapy is the primary treatment for nasopharyngeal carcinoma (NPC) patients due to its anatomic location and radiosensitivity [1]. Clinically, posttreatment recurrence and distance metastases are still obstacles to successful treatment of NPC cases. Therefore, management of inside-field recurrent NPC patients remains a huge clinical challenge.

Some studies speculate that the main reason for the relapse and metastases of NPC may be the presence of cancer stem-like cells (CSCs) [2-4]. CSCs tend to repopulate malignant tumors during radiotherapy and accelerated tumor repopulation is a major cause of radiotherapy failure [5]. In addition, there are also studies shown that CSCs contribute to radioresistance through preferential activation of autophagy and an increase in DNA-repair capacity [6, 7]. Although such assumption and conclusion are based on strong clinical and experimental rationality, the identity of these stem cells and the nature of their interaction with ionizing radiation (IR) remain obscure.

Recently, autophagy has been shown to help in acquisition of resistance in CSCs towards anticancer therapy in various cancers $[8,9]$. There are studies shown that autophagy plays an important role in the stem maintenance [10], DNA damage repair [11, 12] 
and radioresistance[13]. Increased autophagy activity can cause resistance to IR [14]. Therefore, targeting autophagy in CSCs may aid to enhance the radiosensitivity of nasopharyngeal cancer and reduce tumor recurrence or metastasis. However, the therapeutic promise is not to be verified experimentally yet.

Clioquinol (CQ), a Chloroquine analogue, autophagy inhibitor which prevent autophagosome maturation, has been shown to increase the anticancer activity of various chemotherapeutic drugs in different cancer cells [15-17]. And we have previously found that CQ could target zinc to lysosome, leading to alterations of lysosome integrity and lysosome-mediated apoptotic cell death [18]. Moreover, CQ can also suppress NF-kB activity, which is more pronounced in the presence of zinc [19]. However, the role of CQ combined with zinc to IR in nasopharyngeal cancer stem cell is not yet reported.

The aim of this study is to explore the causes of inside-field recurrence of NPC patients after definitive radiotherapy. We observed that the presence of stem cells and increased autophagy activity played an important role in this process. Subsequently, we identified the possibility of radiosensitization of CQ combined with zinc in NPC stem-like cells, and explored the molecular mechanisms which were implicated in this process.

\section{Materials and Methods}

\section{Patients selection}

This study was approved by the Zhongnan Hospital of Wuhan University Ethics and Scientific Committee (2019040). All patients had signed written informed consent. The inclusive criteria were as follows: (1) histologically confirmed NPC before first treatment, (2) primarily treated with concurrent chemo-radiotherapy (CCRT) or IMRT alone with or without neoadjuvant/adjuvant chemotherapy, (3) finished the entire course of definitive radiotherapy, (4) received re-biopsy and confirmed by the pathological diagnosis for the local recurrence. Sixty of 541 patients with pathologically confirmed NPC were included in the present study from the Department of Radiation and Medical Oncology, Zhongnan Hospital of Wuhan University the from November 2011 to July 2018. Inside-field recurrence was defined as $95 \%$ or more of the r-GTVnx or r-GTVnd volume within the $95 \%$ isodose of PTVnx or GTVnd [20]. The detailed sites of local recurrence were judged by three senior attending radiation oncologists.

\section{Cell cultures and sorting of cell populations}

The CNE-2 cell line was presented from Prof. Yunfei Xia at Sun Yat-sen University Cancer Center (Guangzhou, China)[21]. CNE-2 cell was cultured in RPMI-1640 medium (Hyclone, Logan, UT, USA) with $10 \%$ fetal bovine serum (Hyclone), 100 units $/ \mathrm{ml}$ penicillin and $100 \mathrm{mg} / \mathrm{ml}$ streptomycin (Hyclone). The Sorting of cell populations was referred to a previously reported method [22]. Sorted CNE-2s cell was cultured in DMEM/F12 (1:1) medium (Hyclone)

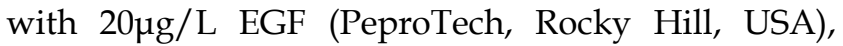

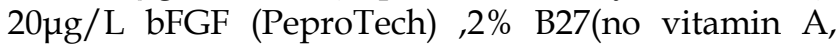
Gibco, Carlsbad, Calif, USA),100 units/ml penicillin and $100 \mathrm{mg} / \mathrm{ml}$ streptomycin (Hyclone). All the two cell lines were cultured in a $37^{\circ} \mathrm{C}$ incubator (Sanyo, Japan) with $5 \% \mathrm{CO}_{2}$. Cells were digested by $0.25 \%$ trypsin and $0.02 \%$ EDTA solution (Sigma, St. Louis, $\mathrm{MO}$, USA).

\section{Colony formation assay}

A colony formation assay was used to analyze cell renewal ability and evaluate radio- sensitivity. Viable CNE-2s and CNE-2ns cells (100, 200, 400, 800, 1000 and 2000 cells/well) were seeded in 6-well plates. Once cell adhered, $1 \mu \mathrm{M}$ CQ (Sigma, St. Louis, MO, USA) and $10 \mu \mathrm{M}$ zinc (Sigma) were added to the medium. After incubation for $6 \mathrm{~h}$, the plates were irradiated with 0, 1, 2, 4, 6, 8 and 10 Gray (Gy) sequentially with the Small Animal Radiation Research Platform (SARRP, PXI X-RAD 225Cx, CT, USA) from a 204-kV photon beam. After 10 days, the colonies were fixed with $4 \%$ paraformaldehyde (PFA) and stained with crystal violet. The cells were photographed and the numbers of colonies were counted. A "multitarget-single hitting" model was applied to fit the survival curve.

\section{Flow cytometry}

The CNE-2s cells were placed in 6-well plates were starved for $6 \mathrm{~h}$ and treated with $1 \mu \mathrm{M} C \mathrm{CQ}$ and $10 \mu \mathrm{M}$ zinc for $24 \mathrm{~h}$. The cells were harvested, washed twice with cold PBS, and stained with FITC-conjugated annexin $\mathrm{V}$ for $20 \mathrm{~min}$ and propidium iodide for $5 \mathrm{~min}$ (Sigma-Aldrich) in the dark. The stained cells were assessed by flow cytometry (FACSAria TM[III], BD, Mountain View, USA)), and analyzed by FlowJo vX.0.7 software. The intracellular apoptosis rates were measured by flow cytometry as previously described [20]. Briefly, $5 \times 10^{5}$ cells were seeded in 6-well plates and then treated as indicated. The cells were washed twice with cold PBS and collected for fluorescence analysis using a flow cytometer (FACSAria TM[III], BD). 


\section{Western blotting analysis}

Western blotting was performed as previously described [23]. All the antibodies for western blotting were purchased from Cell Signal Technology (Danvers, MA, USA). The immunoreactive proteins were detected by enhanced chemiluminescence and quantified with image Pro Plus 6.0.

\section{Immunofluorescence staining}

The CNE-2s cells were seeded on $10 \mathrm{~mm}$ coverslips, fixed with $4 \%$ PFA for $30 \mathrm{~min}$, treated by $0.1 \%$ Triton $\mathrm{X}-100$ and blocked in 5\% BSA for $1 \mathrm{~h}$ at room temperature. Sequentially the fixed cells were incubated with primary antibody at $4{ }^{\circ} \mathrm{C}$ overnight, then washed with PBST and incubated with FITC-labelled secondary antibody for $1 \mathrm{~h}$ at room temperature. The nuclei were labelled with DAPI (2 $\mathrm{mg} / \mathrm{ml}$ ), and the immunofluorescence (IF) staining was analyzed using a fluorescence microscope (Olympus IX 73 DP80, Japan). The mean destiny was applied to semi-qualified by Image Pro Plus 6.0.

\section{Autophagosome and autophagy detection}

Transmission electron microscopy (TEM) performed with an H-600IV microscope (Hitachi, Tokyo, Japan) was utilized to analyse ultra-structural images of autophagic vacuoles, auto-phagosomes and autolysosomes by method previously reported[24]. Acridine orange staining method was referred to our previous studies [18]. A GFP-LC3 lentivirus (Genechem, Shanghai, China) was used to facilitate the detection of autophagy. This procedure was performed in accordance with the manufacturer's instructions (Genechem).

\section{Immunohistochemical staining}

Samples from patients and xenograft tumors were fixed using formalin and then used for immunohistochemical staining to measure different protein expression. Tissues were dehydrated in graded ethanol solutions, cleared in xylene, embedded in paraffin and placed onto slides. The slides were incubated with the appropriate antibodies. The Immunohistochemical (IHC) staining was analyzed using a microscope (Olympus IX 73 DP80, Japan). The mean destiny was applied to semi-qualified by Image Pro Plus 6.0.

\section{Animals and In vivo assay}

Six-week-old female BALB/C nu/nu mice were purchased from Beijing Vital River Laboratory Animal Technology (Beijing, China) and all animal experiments were performed according to the Wuhan University Animal Care Facility and National Institutes of Health guidelines. For the tumorigenesis ability test, freshly sorted CNE-2s cells suspended in $200 \mathrm{~mL}$ PBS were inoculated into the flanks of 6- to 7-week-old BALB/c-nu/nu mice. The mice were monitored 10 days for palpable tumor formation and euthanized 14 days after transplantation to assess tumor formation. Tumors were measured using a Vernier caliper, weighed, and photographed.

For the synergic effect test of CQ combined with Zinc and IR, the method was described as follows. Approximately $1 \times 10^{5} \mathrm{CNE}-2 \mathrm{~s}$ cells were harvested, resuspended in $100 \mathrm{ml}$ PBS, and injected subcutaneously into the right flank of each mice. Treatment was commenced when the tumor size reached approximately $200 \mathrm{~mm}$. The mice were randomized into 6 groups and treated as follows: CQ combined with zinc $(10 \mathrm{mg} / \mathrm{kg} C Q+20 \mathrm{mg} / \mathrm{kg}$ zinc i.p. 30min before radiotherapy), radiotherapy (30Gy/3f, irradiation once every other day for one-week, Small Animal Radiation Research Platform SARRP, PXI X-RAD 225Cx, CT, USA), CQ + zinc combined with radiation, rapamycin $+\mathrm{CQ}+$ zinc combined with radiation $(3 \mathrm{mg} / \mathrm{kg}$ rapamycin +10 $\mathrm{mg} / \mathrm{kg} \mathrm{CQ}+20 \mathrm{mg} / \mathrm{kg}$ zinc i.p. 30min before radiotherapy) and saline solution as an untreated vehicle. The size of the subcutaneous tumors and weight of the mice were recorded every 2 days. Before the mice were radiated, we applied X-rays fluoroscopy to confirm the completed foci in the irradiated field. Tumor volume $(\mathrm{V})$ was calculated according to the formula: $\Pi / 6 \times$ length $\times$ width $^{2}$.

\section{Statistical analysis}

Unless stated otherwise, all experiments were conducted in triplicate. Data was expressed as the mean $\pm S D$ of at least 3 independent experiments. The significance of differences between mean values was determined using two-way ANOVA. P value less than 0.05 was considered significant.

\section{Results}

\section{Clinical characteristics of NPC patients}

Sixty patients were included in this study finally. Twenty NPC patients experienced inside-field recurrence after initial definitive radiotherapy treatment, all of them received re-biopsy and were confirmed with pathological diagnosis. Forty matched patients were relapse free with follow up duration more than 3 years. The median follow-up time was 44.9 months (range 30.2 to 64.5 months), and the median age was 47 years (range 31 to 64 years). All patients exhibited non-keratinizing squamous cell carcinoma. The baseline characteristics were shown in Table 1. 
Table 1. Clinical characteristics of NPC patients $(n=60)$

\begin{tabular}{|c|c|c|}
\hline \multirow[t]{2}{*}{ Characteristics } & $\begin{array}{l}\text { Inside-field recurrence }(n= \\
20)\end{array}$ & $\begin{array}{l}\text { Without recurrence }(n= \\
\text { 40) }\end{array}$ \\
\hline & No. of cases $(\%)$ & No. of cases $(\%)$ \\
\hline \multicolumn{3}{|l|}{ Gender } \\
\hline Male & $15(75 \%)$ & $30(75 \%)$ \\
\hline Female & $5(25 \%)$ & $10(25 \%)$ \\
\hline \multicolumn{3}{|c|}{ WHO Histologic type } \\
\hline IIa & $4(20 \%)$ & $8(20 \%)$ \\
\hline $\mathrm{IIb}$ & $16(80 \%)$ & $32(80 \%)$ \\
\hline \multicolumn{3}{|l|}{ T classification } \\
\hline $\mathrm{T} 1$ & $2(10 \%)$ & $5(13 \%)$ \\
\hline $\mathrm{T} 2$ & $8(40 \%)$ & $16(40 \%)$ \\
\hline $\mathrm{T} 3$ & $7(35 \%)$ & $15(38 \%)$ \\
\hline $\mathrm{T} 4$ & $3(15 \%)$ & $4(9 \%)$ \\
\hline \multicolumn{3}{|l|}{$\mathrm{N}$ classification } \\
\hline N1 & $1(5 \%)$ & $6(15 \%)$ \\
\hline N2 & $16(80 \%)$ & $28(70 \%)$ \\
\hline N3 & $3(15 \%)$ & $6(15 \%)$ \\
\hline \multicolumn{3}{|l|}{ Clinical stage } \\
\hline I & $0(0 \%)$ & $0(0 \%)$ \\
\hline
\end{tabular}

\begin{tabular}{|c|c|c|}
\hline \multirow[t]{2}{*}{ Characteristics } & \multirow{2}{*}{$\begin{array}{l}\text { Inside-field recurrence }(\mathrm{n}= \\
20) \\
\text { No. of cases }(\%)\end{array}$} & \multirow{2}{*}{$\begin{array}{l}\text { Without recurrence }(n= \\
40) \\
\text { No. of cases }(\%)\end{array}$} \\
\hline & & \\
\hline$\overline{\text { II }}$ & $1(5 \%)$ & $2(5 \%)$ \\
\hline III & $14(70 \%)$ & $28(70 \%)$ \\
\hline $\mathrm{IVa}+\mathrm{IVb}$ & $5(25 \%)$ & $10(25 \%)$ \\
\hline \multicolumn{3}{|l|}{$\begin{array}{l}\text { Neoadjuvant } \\
\text { chemotherapy }\end{array}$} \\
\hline Yes & $17(85 \%)$ & $32(80 \%)$ \\
\hline No & $3(15 \%)$ & $8(20 \%)$ \\
\hline \multicolumn{3}{|l|}{$\begin{array}{l}\text { Concurrent } \\
\text { chemotherapy }\end{array}$} \\
\hline Yes & $13(65 \%)$ & $25(62 \%)$ \\
\hline No & $7(35 \%)$ & $15(38 \%)$ \\
\hline \multicolumn{3}{|l|}{ PTV-GTVt dose } \\
\hline$\geq 70 \mathrm{~Gy}$ & $18(90 \%)$ & $36(90 \%)$ \\
\hline$<70$ Gy & $2(10 \%)$ & $4(10 \%)$ \\
\hline \multicolumn{3}{|c|}{ Radiotherapy modality } \\
\hline IMRT & $20(100 \%)$ & $40(100 \%)$ \\
\hline $3 \mathrm{D}-\mathrm{CRT}$ or $2 \mathrm{D}$ & 0 & 0 \\
\hline
\end{tabular}

A

case1

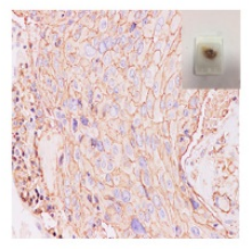

B

LC3
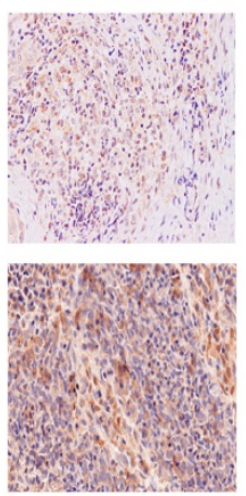

case2
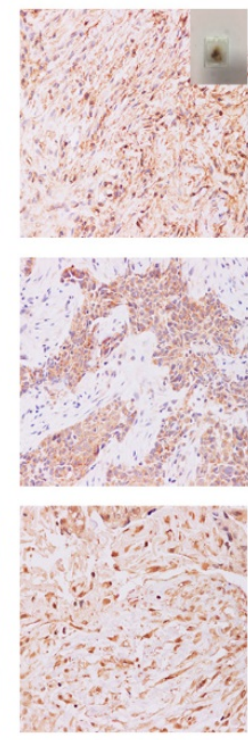

case 3
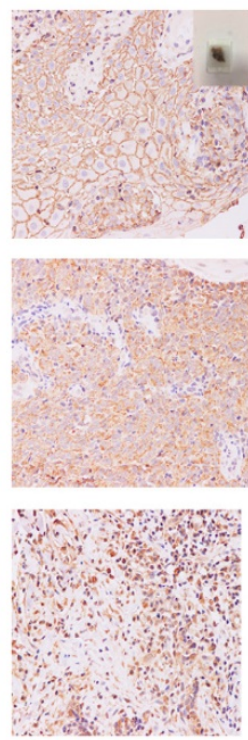

case 4
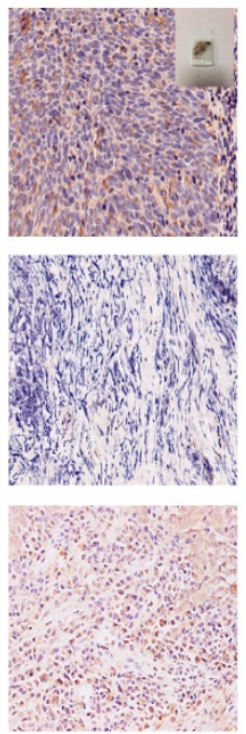

case 5
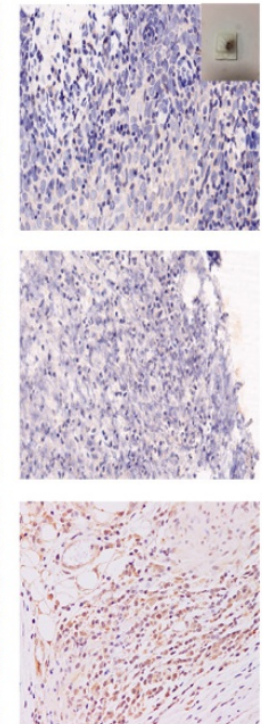

C

CD44

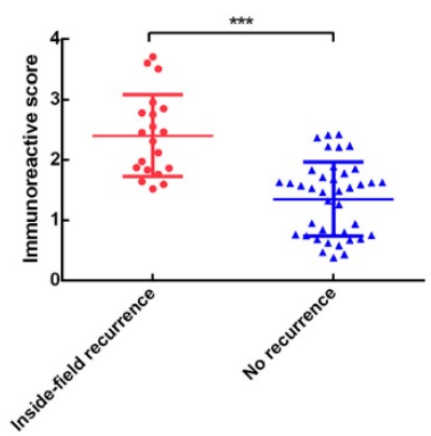

Beclin1

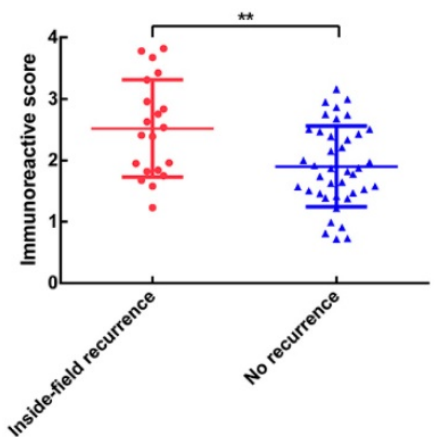

LC3

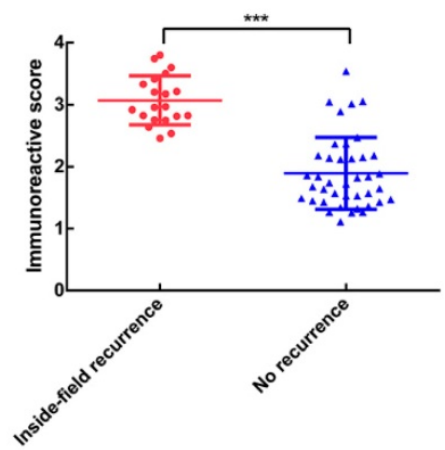

Fig. 1: High levels of CD44, Beclin1, LC3 in 60 NPC patients. (A) Representative IHC images of CD44; case 1-3 represent NPC patients with inside-field recurrence and case 4-5 represent ones with relapse free. (B) Representative IHC images of Beclin I and LC3. (C) Scatter plot of the protein levels of CD44, Beclin 1, LC3 for the NPC patients with and without inside-field recurrence. Immunoreactivity was analyzed in 5 random areas for each pathological section and was scored as $0+($ no staining), $1+($ weak staining), $2+$ (moderate staining), $3+($ strong staining), $4+$ (very strong staining). $(*, \mathrm{P}<0.05 ; * *, \mathrm{P}<0.01 ; * * *, \mathrm{P}<0.001)$. 
A

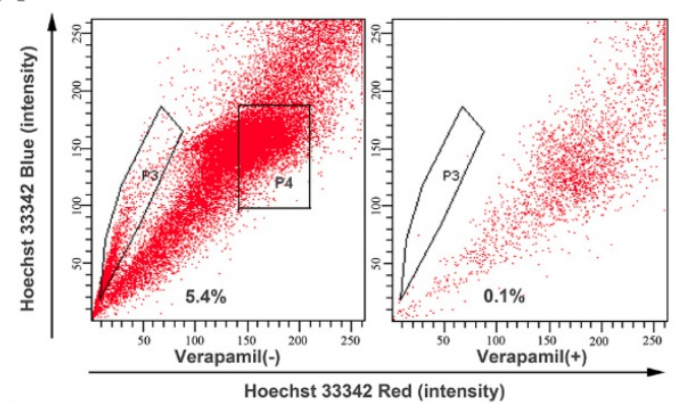

D

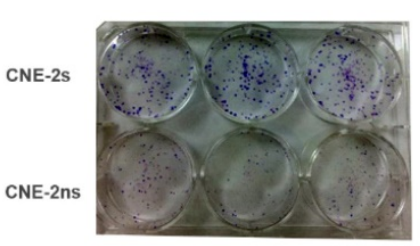

$\mathbf{F}$
B

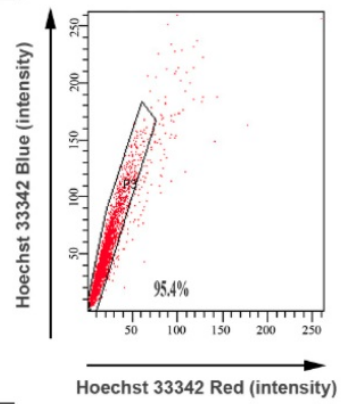

E

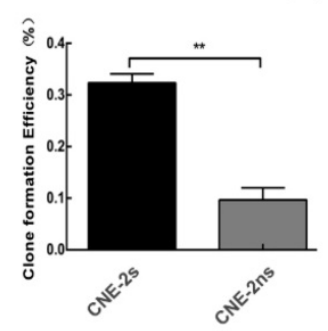

C

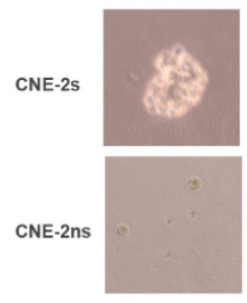

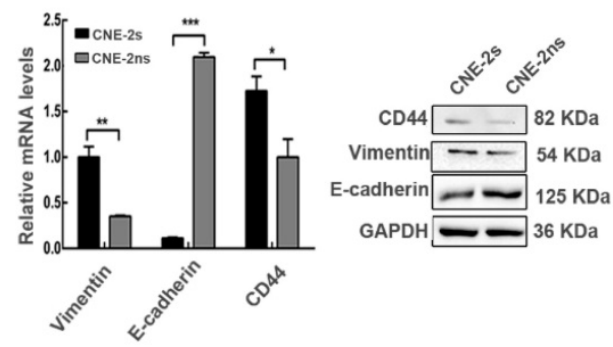
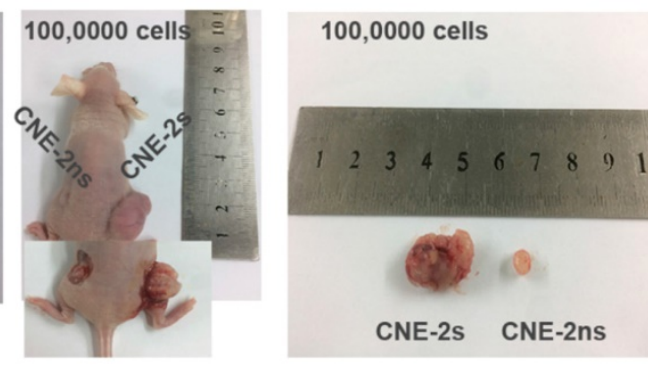

\begin{tabular}{c|c|c|c|c|}
\multicolumn{1}{c}{} & \multicolumn{1}{c}{$1 \times 10^{6}$} & $5 \times 10^{5}$ & $1 \times 10^{5} 5 \times 10^{4}$ \\
\cline { 2 - 5 } CNE-2S & $6 / 6$ & $6 / 6$ & $4 / 6$ & $2 / 6$ \\
\cline { 2 - 5 } CNE-2ns & $2 / 6$ & $0 / 6$ & - & - \\
\cline { 2 - 5 } & & \multicolumn{3}{c}{-}
\end{tabular}

Fig. 2: Side population cells were isolated from nasopharyngeal cancer cell (CNE-2) and characterized with stem cell properties. (A) sorting of CNE-2 cells by flow cytometry. (B) the sorting purity of the freshly sorted SP cells. (C) the CNE-2s and CNE-2ns cells were seeded in tumor sphere culture medium. (D) clone formation results and statistical analysis. (E) the CNE-2s and CNE-2ns cells lysates were analyzed by Western blotting and Realtime-qPCR with anti-CD44, anti-E-cadherin and anti-Vimentin. GAPDH served as a loading control. (All data represent the mean \pm SD; $n=3$; *, $P<0.05 ; * *, P<0.01$; ***, $P<0.001$ ) (F) the indicated amounts of $C N E-2 s$ and $C N E-2 n s$ cells were transplanted into 6 weeks $B A L B / c-n u$ mice.

\section{High expression levels of CD44, autophagy-related proteins (Beclin 1 and LC3) in NPC patients with inside-field recurrence}

We then adopted immunohistochemical assays to examine the protein expression pattern of CD44, Beclin1 and LC3 in 60 NPC cases. Compared with the relapse free NPC patients, NPC patients with insidefield recurrence had higher levels of CD44 proteins in tumor tissues (Fig. 1A). Furthermore, the expression levels of Beclin1, LC3 proteins, which presented high autophagy activity, were significantly higher in NPC patients with inside-field recurrence (Fig. 1B). Fig. 1C showed scatter diagrams of the protein levels of CD44, Beclin1, LC3 for the NPC patients with and without inside-field recurrence. The results implicated the existence of cancer stem cells and increased autophagy activity played critical roles in the inside-field recurrence of NPC.

\section{Successfully establishing and characterizing of CNE-2 stem-like cells}

Next, we attempted to isolate cancer stem-like cells from CNE-2 cell line by flow cytometry. The sorting referred to previous reports [22]. CNE-2s cells occupied $5.4 \%$ of the total cells (Fig. 2A). CNE-2s (P3) and CNE-2ns (P4) cells were collected for subsequent experiments; the purity of CNE-2s cells was $96 \%$ (Fig. 2B). The sorted CNE-2s and CNE-2ns cells were cultured in serum-free medium, CNE-2s cells showed clear microsphere formation after 5 days, while CNE-2ns cells were still scattered and grew slowly (Fig. 2C). The Clone Formation Efficiency (CFE) of CNE-2s and CNE-2ns cells was (32.33 \pm 3.055$) \%$ and 
$(9.67 \pm 4.041) \%$ respectively. There was a significant difference in CFE between the two groups $(\mathrm{P}<0.001$; Fig. 2D). The mRNA and protein expression levels of stem cell-related gene CD44, interstitial cell-related genes E-cadherin and Vimentin were also detected in two cell lines. Results were shown in Fig. 2E. Compared with CNE-2ns cells, the mRNA and protein expression of CD44 and Vimentin in CNE-2s cells were higher $(\mathrm{P}<0.05$ for $\mathrm{CD} 44$ and $\mathrm{P}<0.01$ for Vimentin), E-cadherin were lower $(\mathrm{P}<0.001)$. To further explore whether CNE-2s cells had stem-like cells activity, the same concentrations of CNE-2s and CNE-2ns cells were inoculated subcutaneously in the left and right hind legs of BALB/c-nu female nude mice. The tumors volume of CNE-2s cell was also significantly larger than that of CNE-2ns cells with the same concentration of tumor cells, suggesting that the sorted CNE-2s cells had stem-like cells activity and could be used as models for stem cells research. The expression of CD44, Vimentin and E-cadherin were consistent with our in vitro results and there was no significant difference in the expression of Beclin1 and LC3 in these two tissues (Additional file 2: Fig. S1).

\section{CNE-2s cells are resistant to radiotherapy through activation of autophagy}

We then explored the association between autophagy and radioresistance in vitro. After different doses of ionizing radiation (IR) treatment, the colony formation rates of both were counted. The survival fraction of CNE-2s cells was higher than that of CNE-2ns cells at the same dose (Fig. 3A), and the SF2 value was significantly higher than that of CNE-2ns cells $(0.617 \pm 0.012$ and $0.180 \pm 0.011, P<0.01)$. After 4 Gy IR treatment, total cellular protein was extracted and the autophagy levels were observed. It was found that the expression levels of autophagy-related proteins Beclin1 and LC3 in CNE-2s cells were significantly higher than that in CNE-2ns cells (Fig. 3B). The results showed that CNE-2s cells might be realized radioresistance through activation of autophagy.

\section{CQ combined with zinc enhances radiosensitivity of CNE-2s cells through the inhibition of autophagy}

In order to determine whether $\mathrm{CQ}$ combined with zinc could increase sensitivity of CNE-2s cells to radiation, the colony formation assay was used. The results were shown in the Fig. 4A. Survival fraction of $1 \mu \mathrm{M}$ CQ combined with $10 \mu \mathrm{M}$ zinc administration was lower than IR alone (IR group). There was no significant difference in survival fraction between the groups of CQ combined with zinc and one with pretreated with rapamycin for two hours. Acridine orange staining and GFP-LC3 were introduced to detect the autophagy. Four Gy IR could enhance the intensity of orange-red fluorescence in CNE-2s cells. However, CQ combined with zinc could decrease the intensity of orange-red fluorescence induced by $4 \mathrm{~Gy}$ IR in CNE-2s cells (Fig. 4B). The GFP-LC3 fusion protein particles were transferred into $\mathrm{CNE}-2 \mathrm{~s}$ cells and then given different treatments. After 24 hours the number of fluorescent spots in the 4 Gy group was increased compared with the control group (Fig. 4C). Subsequently, we observed the structure and the number of autophagosomes in different treatment groups using transmission electron microscope. It was found that autophagosomes were mainly monolayer and bilayer membrane structures, containing some cytoplasmic components. Four Gy IR could increase the numbers of autophagosomes. In the group of CQ combined with zinc with $4 \mathrm{~Gy}$, the autophagosomes became more monolayer and larger in size (Fig. 4D). The expression of Beclin1 and LC3II/LC3I proteins in the 4 Gy treated group was higher than that in the control group (Fig. 4E). These results indicated that CQ combined with zinc could inhibit autophagy to realize radiosensitization of $\mathrm{CNE}-2 \mathrm{~s}$ cells.
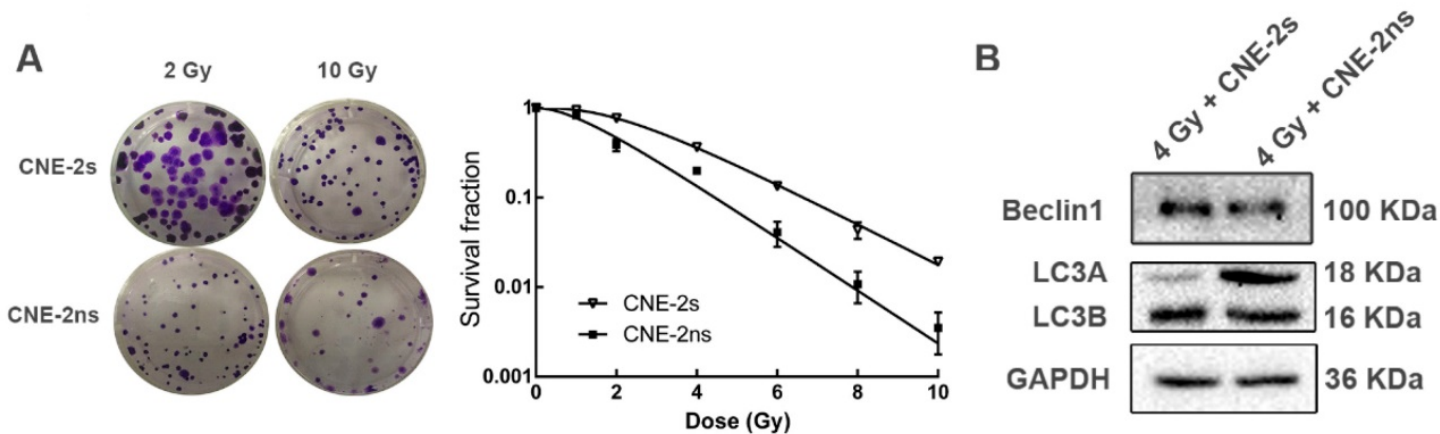

Fig. 3: Comparison of radiosensitivity and autophagy levels in CNE-2s and CNE-2ns cells. (A) colony-formation assay for CNE-2s and CNE-2ns cells using irradiated ( 2 Gy and $10 \mathrm{~Gy}$ ). (B) dose-survival curves of irradiated CNE-2s and CNE-2ns cells (range, 0-10 Gy. Data represent the mean $\pm S D ; n=3$ ). (C) Western blotting detection of Beclin 1, LC3A and LC3B in CNE-2s and CNE-2ns cells assessed 24 hours after 4 Gy IR. 
A
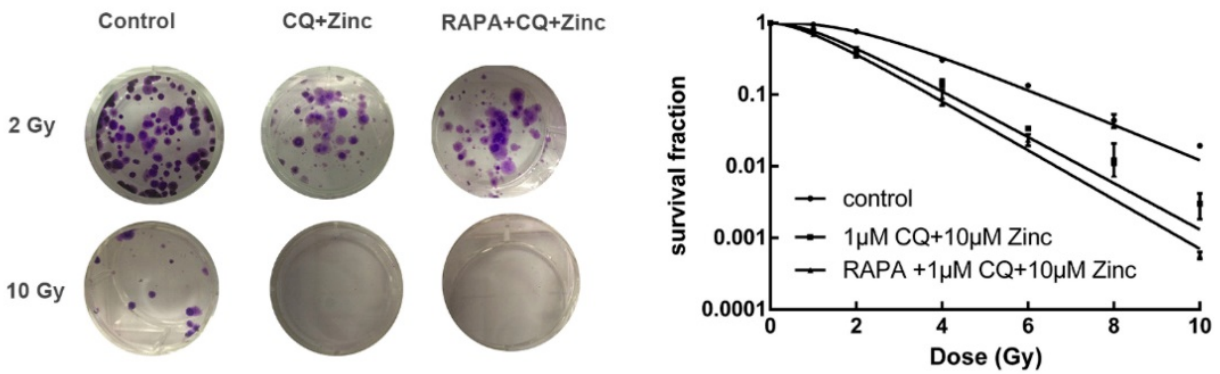

B

Control

$C Q+$ Zinc
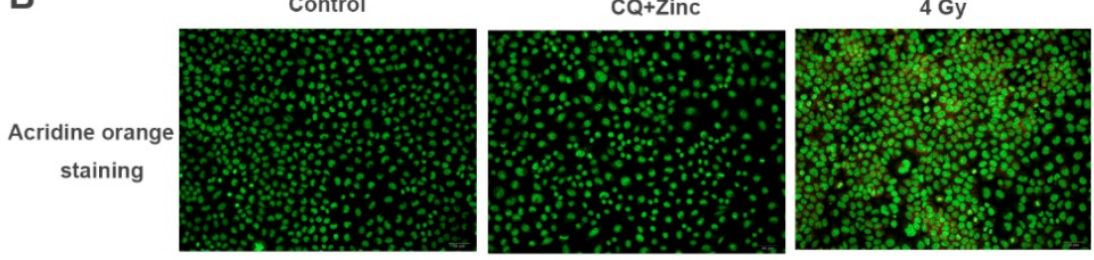

$4 \mathrm{~Gy}+\mathrm{CQ}+\mathrm{Zinc}$

C

Control

$C Q+Z i n c$

4 Gy
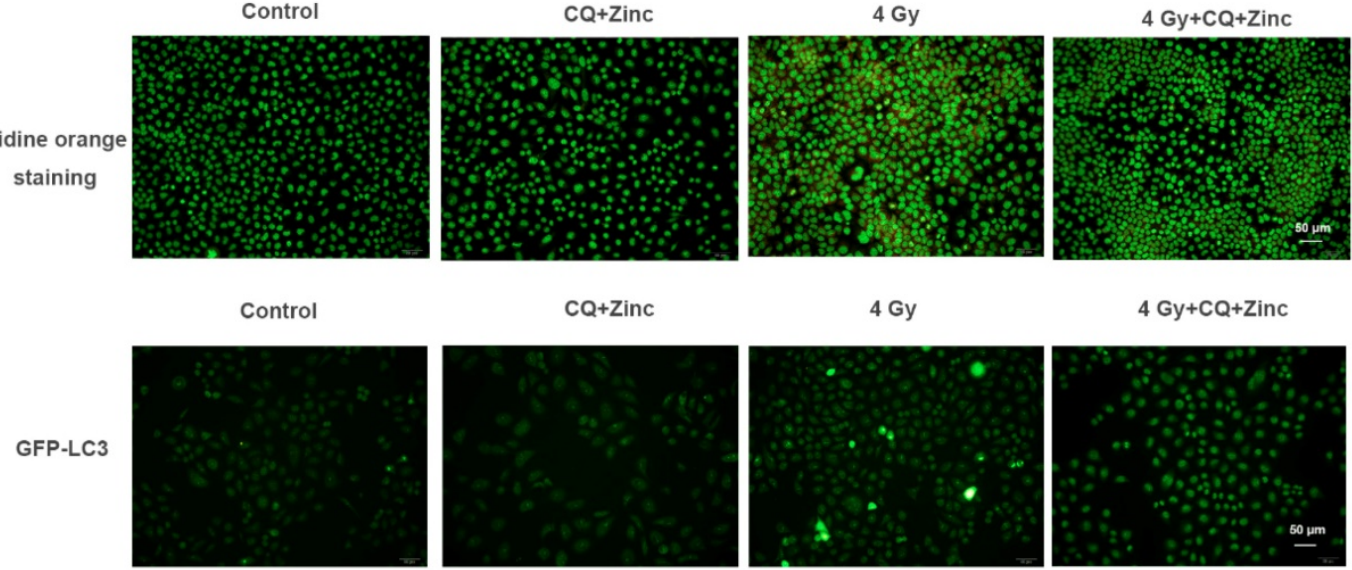

$4 \mathrm{G} y+C Q+Z i n c$

D
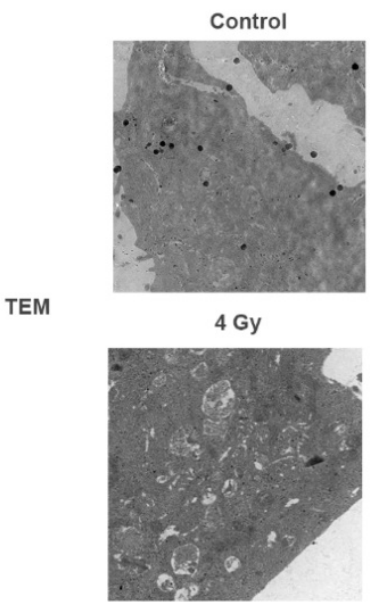

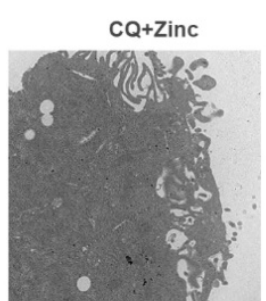

$4 \mathrm{~Gy}+\mathrm{CQ}+\mathrm{Zinc}$

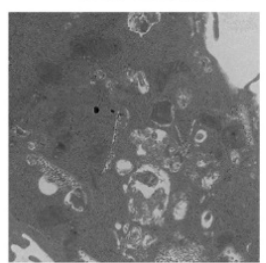

E
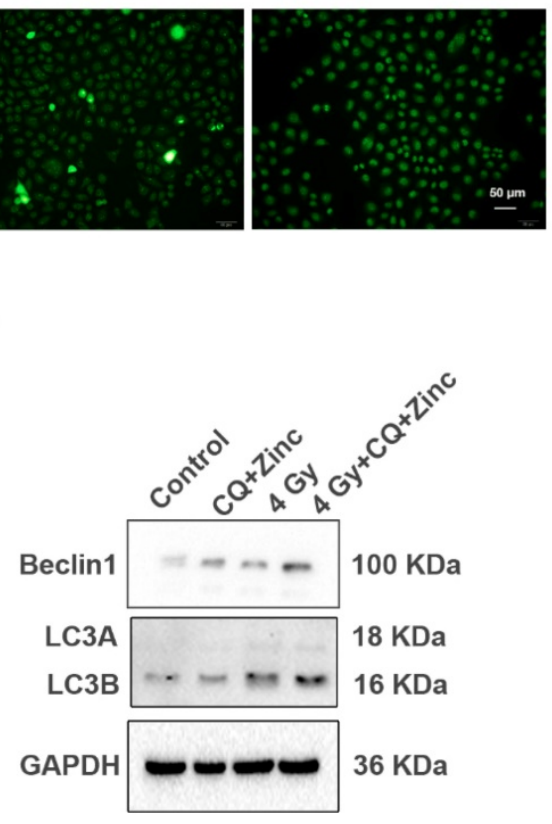

Fig. 4: CQ combined with zinc enhanced the radiosensitivity of CNE-2s cells. (A) Representative crystal violet staining photos of CNE-2s cells irradiated with 2 Gy and 10 Gy. All values shown were mean \pm SD of triplicate measurements and repeated three times with similar results. Clone formation assay was used to detect the radiosensitivity of CNE-2s cells with different treatments. (B) Representative images of acridine orange staining in CNE-2s. (C) Representative images of GFP-LC3 tracer protein. (D) Representative images of transmission electron microscopy to observe the structure and number of autophagosomes. (E) Western blotting analysis of Beclin 1, LC3A and LC3B protein levels in CNE-2s cells.

\section{CQ combined with zinc inhibits DNA-damage repair response through NF-KB signal pathway}

IR activates NF-kB activity and initiates DNA repair processes. We have reported that $\mathrm{CQ}$ combined with zinc could downregulate the NF- $\mathrm{KB}$ activity in many human cancer cell lines [19, 23]. Four Gy IR could significantly enhance the fluorescence intensity of phosphorylated P65 in the nucleus of CNE-2s cells compared with the control group, and CQ combined with zinc administration could reverse the translocation of phosphorylated P65 induced by 4 Gy in CNE-2s cells (Fig. 5A).Beyond that, irradiation could also induce DNA damage, mainly DNA double-strand breaks (DSB) and $\gamma \mathrm{H} 2 \mathrm{AX}$ is considered a specific DSB marker. We assessed phos- $\gamma \mathrm{H} 2 \mathrm{AX}$ foci by IF as shown in Fig. 5B. The CQ combined with zinc group showed a higher mean fluorescence intensity than the control group after 24 hours of radiation exposure. At the same time, we also detected the expression levels of DNA damage and repair proteins and found that the expression of phosphorylated P65, 
Ku70, Ku80, BRCA1, BRCA2, and Rad51 in the group of CQ combined with zinc with 4 Gy was significantly decreased compared with the 4 Gy group, and the phos- $\mathrm{rH} 2 \mathrm{AX}$ expression level in the group of CQ combined with zinc with 4 Gy was much higher than that in the 4 Gy group (Fig. 5C). Results indicated that CQ combined with zinc prolonged DNA damage after radiation, which led to failure in DNA damage repair.

\section{CQ combined with zinc induces apoptosis of CNE-2s cells to IR}

To further analyze the mechanisms of the synergic effect of CQ+Zinc with IR in CNE-2s cells, apoptosis of CNE-2s cells was detected by flow cytometry in different treatment groups. Our results showed that the apoptosis of 4Gy group was increased compared with CQ combined with zinc administration alone $(\mathrm{P}<0.05)$. The administration

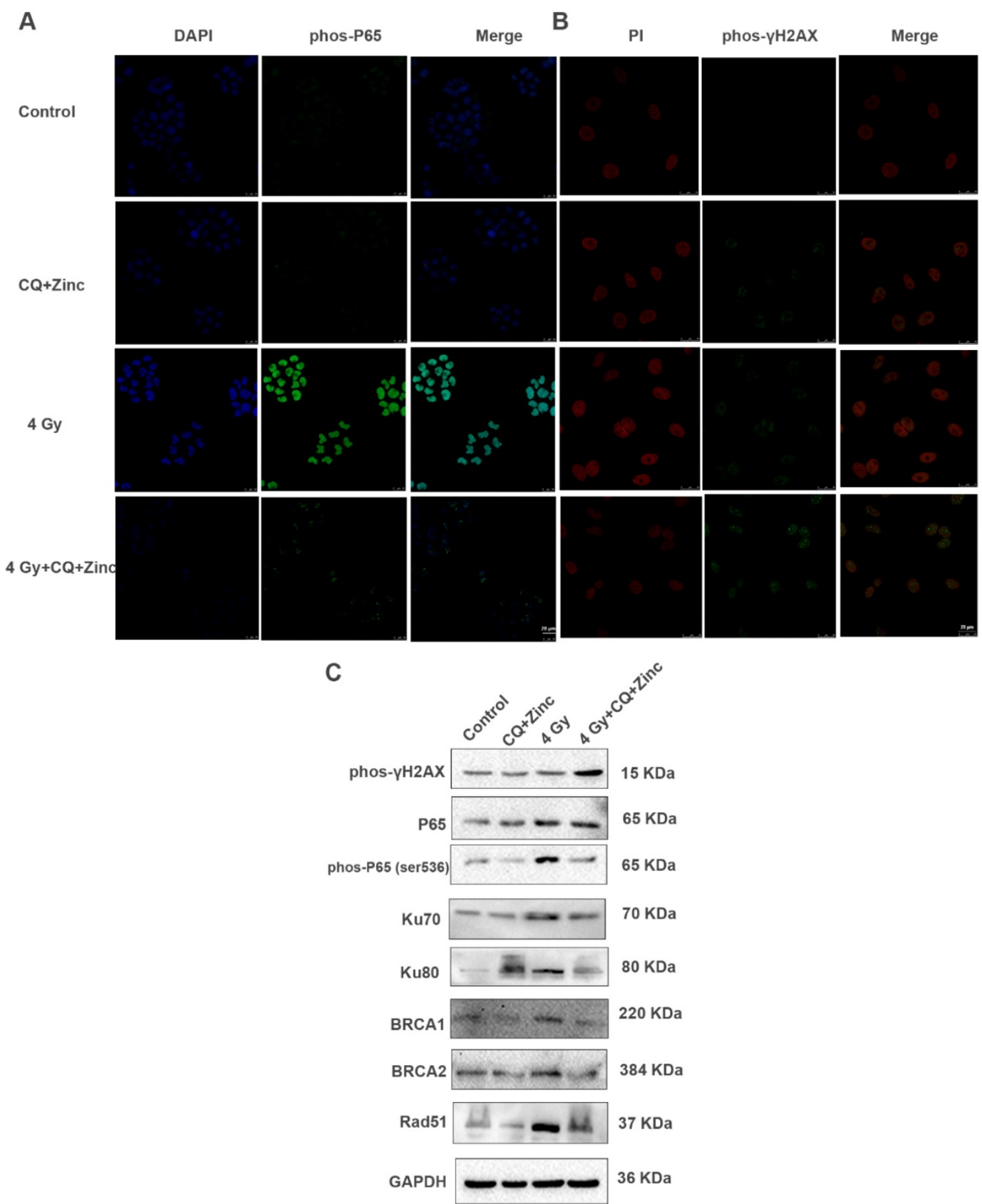

Fig. 5: $C Q$ combined with Zinc suppressed NF-KB activity and increased radiation induced DNA damage. (A) Immunofluorescence staining localization of phospho-p65(phos-P65) in different treatment groups of CNE-2s cells. (B) Immunofluorescence staining of phos- $\mathrm{YH} 2 \mathrm{AX}$. (C)Western blotting analysis of key proteins involved in DNA damage and repair in different treatment groups. 
combined with 4 Gy IR was significantly higher percentage of apoptosis than other groups $(\mathrm{P}<0.001$, Fig. 6A and 6B). IR induced apoptosis through the activation of caspase- 3 in CNE-2s cells, CQ combined with zinc pretreatment could further activate caspase-3, caspase-8, caspase-9, PARP cleavage and Bax, suggesting that $C Q$ combined with zinc enhanced radiation-induced apoptosis of CNE-2s cells through mitochondria and caspase-dependent pathway (Fig. 6C).

\section{CQ combined with zinc increased radiosensitivity of CNE-2s cell in vivo}

To investigate the antitumor effects of CQ combined with zinc in vivo, we examined the therapeutic potential of $C Q$ combined with zinc alone or combined with IR. The results were shown in Fig. 7. The tumor size was slightly decreased in the simple drug-administered group compared with the control group $(p<0.05)$. The tumor volume of the drug-combined X-ray group was significantly smaller than that of the IR alone group, and there was no significant difference in the rapamycin combination group (Fig. 7B, 7C and 7D). The results of immunohistochemistry of tumor tissue showed that the expression of autophagy protein in the drug-combined with IR group was higher than that of the radiotherapy alone group, and there was no significant difference between the rapamycin group and the radiotherapy group (Fig. 7E).

A

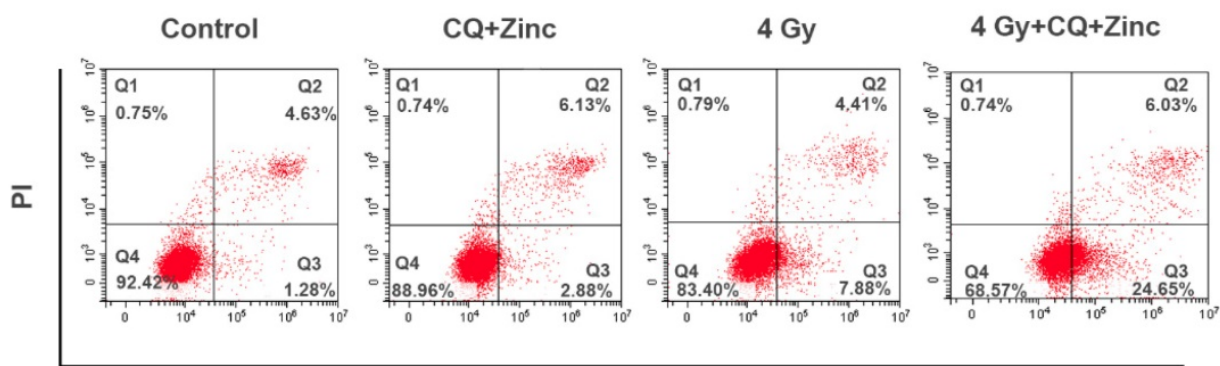

Annexin V-FITC

B

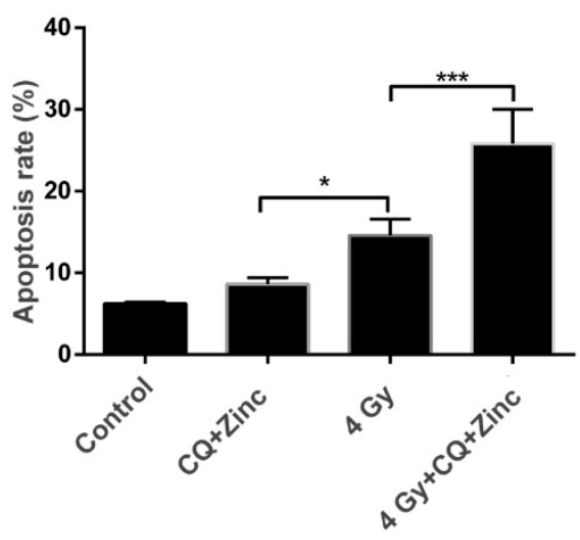

C

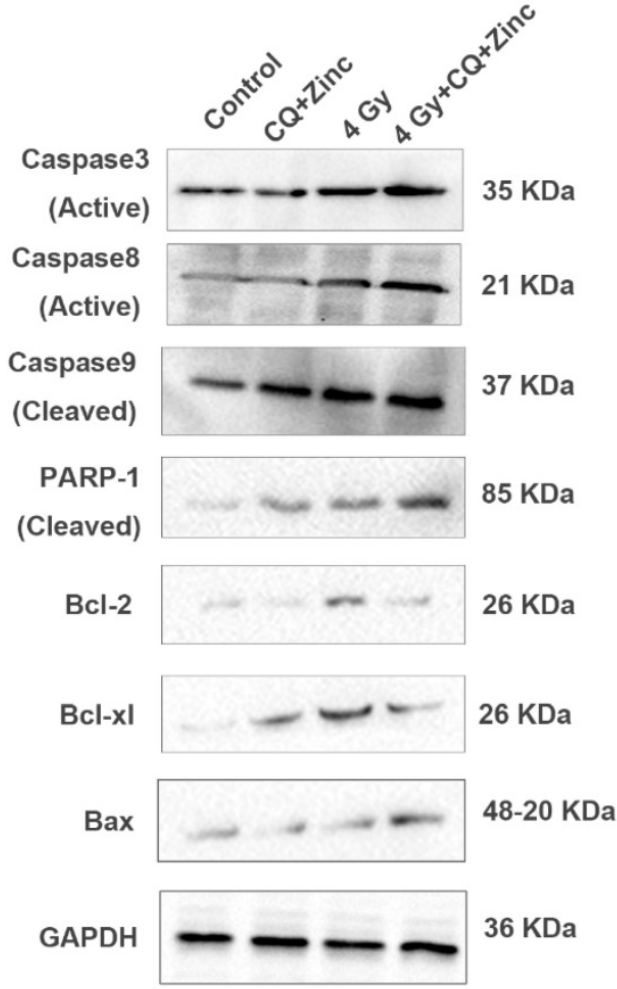

Fig. 6: $C Q$ combined with zinc promoted radiation-induced apoptosis in CNE-2s cells. (A) cell cytometry analysis of Annexin $V$ and PI for apoptosis in CNE-2s cells. (B)the administration treatment group had significantly more cell apoptosis than individual ones. Data were expressed as mean $\pm S D, n=3, * p<0.05$, $* * * p<0.001$. (C) Western blotting analysis of apoptosis-related proteins in different treatment groups. 
A

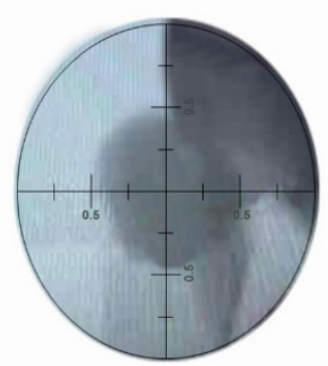

B

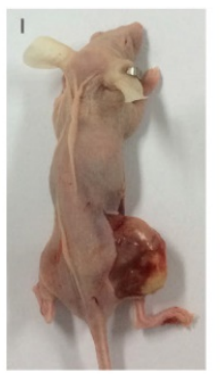

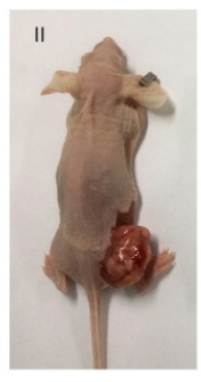

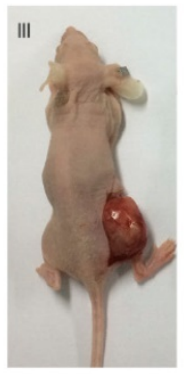

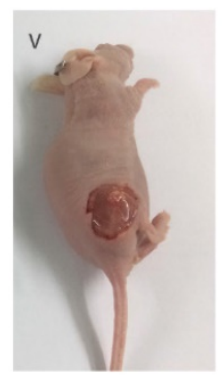

C

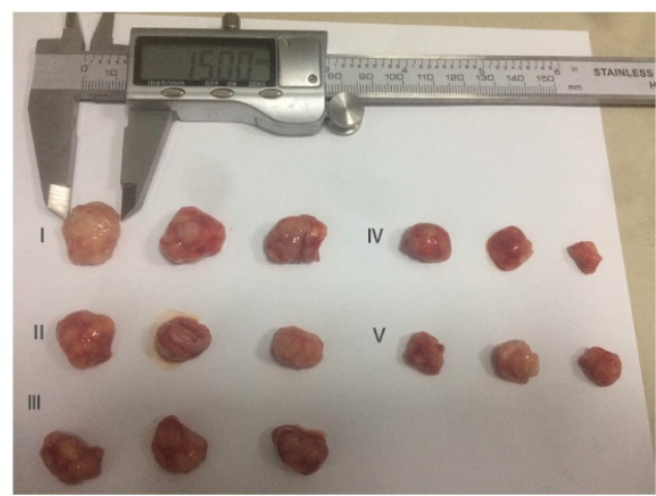

D

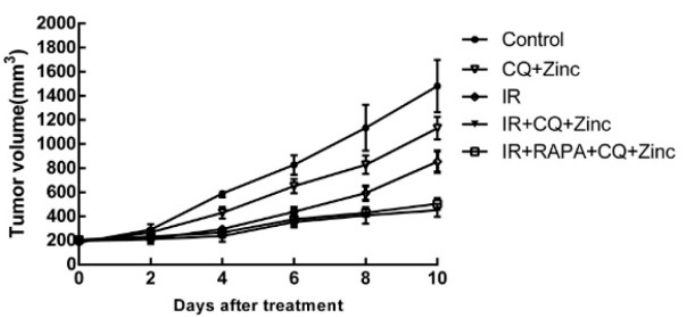

E

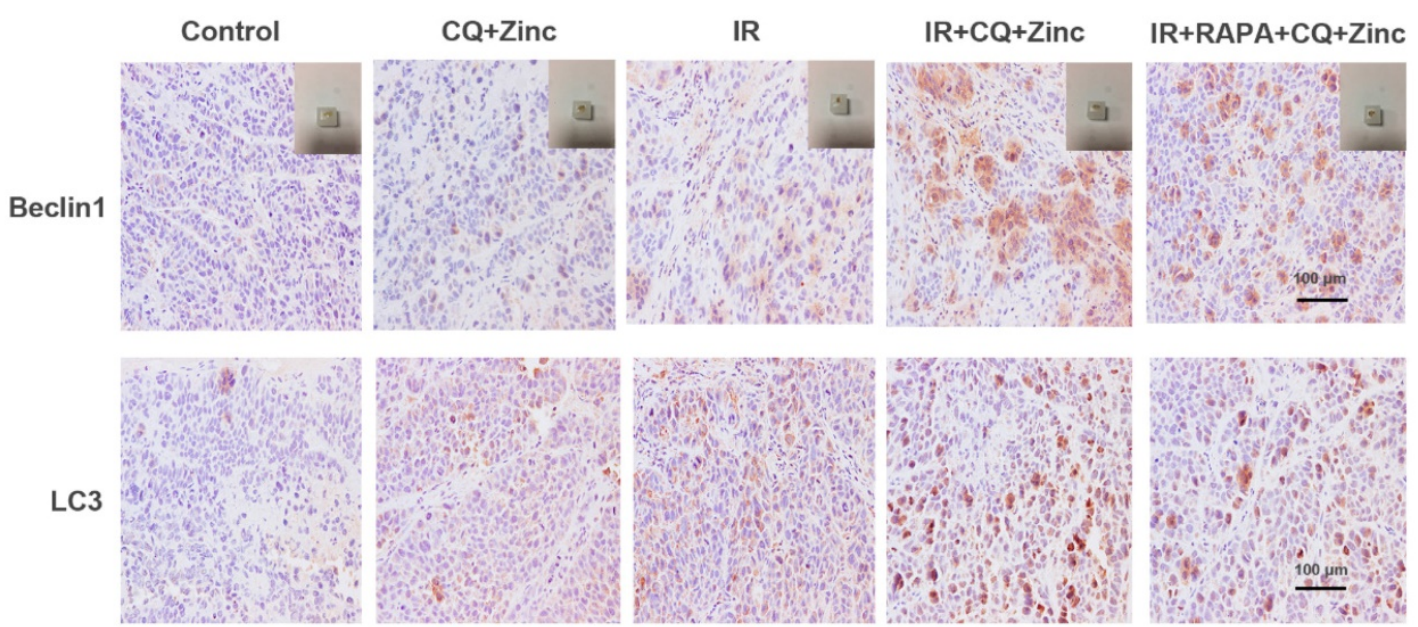

Fig. 7: CQ combined with zinc inhibited tumor growth in vivo. (A) Simulation position before IR. (B) Representative image of tumor growth in different treatments (I, II, III, IV, $\checkmark$ represent control, $C Q+Z i n c, I R, I R+C Q+Z i n c, I R+R A P A+C Q+Z i n c$ respectively). (C) Gross view of tumor. (D) Growth curve of tumor volume. (E) Representative immunohistochemistry staining images of Beclin 1 and LC3 in tumor tissue.

\section{Discussion}

Radiotherapy is the most commonly applied treatment for nasopharyngeal carcinoma (NPC) [25], but we found clinically that some patients experienced tumor recurrence in a short time, which is universal due to radiotherapy resistance. To find out the reason, we collected twenty nasopharyngeal carcinoma patients diagnosed with local inside-field recurrence from our department before July 2018.
Through detecting the expression of stem cells and autophagy related proteins in tumor tissues of these patients, we found some interesting results. Some patients who had inside-field recurrence had higher expression of CD44, autophagy-related proteins. There were reports about the existence of cancer stem cells (CSCs) in NPC $[7,22]$ and CD44 was considered as one of potential surface markers of NPC stem cells $[26,27]$. Hence, we believed that inside-field recurrence of NPC might be related to presence of 
CSCs and autophagy activity. Based on this, we proposed a hypothesis whether it could increase the sensitivity of NPC to radiotherapy by inhibiting autophagy of CSCs.

In order to confirm our assumption, We sorted CNE-2 stem-like (CNE-2s) cells and CNE-2 non-stem-like (CNE-2ns) cells from CNE-2 cells which were the most poorly differentiated NPC cell line[26, 28]. CSCs possessed the ability to initiate tumor growth and sustain self-renewal as well as metastatic potential $[22,29]$. These characteristics were used to identify the presence of stem-like cells. In vitro experiments, our results showed that CNE-2s cells had stronger self-renewal activity than CNE-2ns cells. It is known that epithelial-mesenchymal transition (EMT) is closely related to increase the stemness and metastasis of cancer cells [30]. In our study, expressions of EMT-related genes and proteins in CNE-2s cells were higher than CNE-2ns cells, suggesting that CNE-2s cells had higher metastasis activity. Above results proved that the sorted CNE-2s cells had properties of CSCs and the CSCs model was successfully established. Subsequently, we compared the radiosensitivity and autophagic activity of the two cells. We further discovered and identified the radioresistance and enhanced autophagy activity of NPC CSCs induced by radiation.

As has been previously reported, the maintenance of stemness characteristics is closely related to autophagy activity [31]. And autophagy may play a critical role in determining radiosensitivity of cancer cells [31, 32]. To determine whether the increased radiation sensitivity in CNE-2s resulted from autophagy inhibition, we introduced autophagy activator rapamycin, which could upregulate autophagy activity of cancer stem cells after IR [33], we applied rapamycin in addition to the administration of CQ combined with zinc and IR on CNE-2s cells. As shown in the Results section, the triple treatment group (IR + Rapamycin + CQ +Zinc) had an increased radiosensitivity compared with IR alone, but there was no statistically significant difference compared with the double treatment group (IR + CQ + Zinc). Based on these results, we speculated that CQ combined zinc achieved radiosensitivity through the inhibition of autophagy. To confirm the observed link between CQ + Zinc and autophagy, we detected autophagy activity of CNE-2s cells using acridine orange (AO) staining, transmission electron microscope (TEM), GFP-LC3 tracer and western blotting. Our results showed that IR could significantly induce autophagic change and increase LC3-II protein levels in NPC CSCs. When NPC cells were pretreated with CQ combined with zinc in vitro, autophagy activity was markedly decreased. Hence, we showed that CQ combined with zinc might inhibit autophagy activity induced by IR, which resulted in an increased radiosensitivity in CNE-2s.

Our previous study demonstrated that CQ combined with zinc could inhibit NF-kB activation induced by IR in HeLa cells [23].It is well known that NF-kB plays a critical role in cellular protection against a variety of apoptotic stimuli, including DNA damage, and inhibition of NF- $\mathrm{kB}$ leads to radiosensitization [34]. Blocking radiation-induced NF- $\mathrm{kB}$ activation has been shown to increases apoptotic response and decreases growth and clonogenic survival of several human cancer cells [35-37]. Upon activation, NF- $\mathrm{kB}$ translocates into the nucleus, binds sequence-specifically to the promoter/enhancer region of various DNA repair genes and transactivates their expression [38]. This might allow the cancer cells that are surviving the radiation exposure to develop a clone (clonal selection), re-grow (tumor cell proliferation and growth), and cause tumor relapse [39]. Our current study indicated that IR would induce activation of NF- $\mathrm{KB}$ and increase NF- $\mathrm{BB}$ DNA-binding activity. However, CQ combined with zinc could prevent NF$\mathrm{\kappa B} / \mathrm{P} 65$ translocation to the nucleus and decrease the expression of several proteins encoded by NF-kB dependent genes. IR could induce various forms of DNA damage include breaking the bases and cleavage of the DNA backbone, resulting in DNA single strand breaks (SSBs) and double strand breaks (DSBs) [40]. $\gamma \mathrm{H} 2 \mathrm{AX}$ is a highly specific and sensitive molecular marker for monitoring both DSBs initiation and resolution[41]. We found that phosphorylation of histone $\mathrm{\gamma H} 2 \mathrm{AX}$ was enhanced by combination treatment with CQ combined with zinc and 4 Gy compared with IR alone, suggesting that CQ combined with zinc might be blocking DNA damage-repair pathways induced by IR in CNE-2s cells. Two main pathway are responsible for DNA DSB repair, which are NHEJ and HR [42].In this study, we found that CQ combined with zinc remarkably down-regulated the key proteins including BRCA1, BRCA2, RAD-51 (HR pathway) as well as Ku70 and 80 (NHEJ pathway) in NPC stem-like cells, suggesting radiosensitization induced by CQ combined with zinc might be mediated by suppression of DNA damage repair [43].

Radiotherapy prolongs patient's survival through decreasing proliferative capacity and killing tumor cells [44]. However, repopulation of tumor cells during or after IR is an important obstacle to achieve the desired response [45]. Prominent hallmark of cancer are apoptosis evasion and the ability to self-govern and proliferation [46]. Following 
radiation, cancer cell death may occur mainly through necrosis, autophagy and apoptosis [47]. Autophagy is induced in response to many stresses that ultimately lead to apoptosis [48]. NF-kB induces activation of apoptosis inhibitor. IR might promote apoptosis pathway through activation of the caspase cascade. Recruit of caspase inhibitor with radiation to stimulate autophagy pathway may be a useful strategy to increase survival times of patients and a remarkable delay in tumor recurrence [49]. Our results showed that CQ combined with zinc increased IR-induced apoptosis, indicating its potential roles of inhibitor.

In this study, we demonstrated that the presence of cancer stem cells and activated autophagy might be the cause of inside-field recurrence of NPC patients after definitive radiotherapy. CQ combined with zinc had the effect of radiosensitization for NPC CSCs in vitro and in vivo. Mechanistically, clioquinol combined with zinc could inhibit inherent and IR-induced autophagy activity, delay DNA damage repair and induce apoptosis in NPC stem-like cells. This study provided an important and new therapeutic direction for recurrence NPC patients.

\section{Abbreviations}

NPC: Nasopharyngeal carcinoma

FACS: Fluorescence-activated cell sorting

CSCs: Cancer stem cells

Bcl-2: B cell Lymphoma-2

SP: Side population cells

Bax: Bcl-2 Associated X protein

NSP: Non-side population cells

PARP-1: Poly (ADP-ribose) Polymerase

$\gamma$-H2AX: $\gamma$-H2A Histone Family Member $X$

CQ: clioquinol

AO: Acridine orange

BRCA1: Breast Cancer Susceptibility Genes 1

TEM: Transmission Electron Microscope

RAD51: RAD51 Recombinase

IR: Ionizing radiation

Caspase: Cysteine-aspartic Proteases

IF: Immunofluorescence

DSBs: DNA double-stand breaks

IHC: Immunohistochemistry

\section{Supplementary Material}

Supplementary figure.

http://www.ijbs.com/v16p0777s1.pdf

\section{Acknowledgements}

This work was supported by the National Natural Science Foundation of China (Grant No. 81201755 and 81703872), Natural Science Foundation of Hubei province (Grant No. 2018CFB561) and
Zhongnan Hospital of Wuhan University Science, Technology and Innovation Seed Fund (Grant No. ZNPY2016043). The funding body had no role in the design of the study and collection, analysis, and interpretation of data and in writing the manuscript. Besides these, we are grateful to Prof. Yunfei Xia (Department of Radiation Oncology, Sun Yat-sen University Cancer Center) for providing us with CNE-2 cells and Dr. Yingming Sun (Department of Radiation and Medical Oncology, Zhongnan Hospital of Wuhan University) for his technical help.

\section{Ethics approval and consent to participate}

All human samples were collected with the informed consent of the patients and the experiments were approved by the ethics committee of Zhongnan Hospital of Wuhan University. The animal studies were approved by the Institutional Animal Care and Use Committee of Zhongnan Hospital of Wuhan University.

\section{Availability of data and material}

The datasets used and analysed during the current study are available from the corresponding author on reasonable request.

\section{Competing Interests}

The authors have declared that no competing interest exists.

\section{References}

1. Chua MLK, Wee JTS, Hui EP, Chan ATC. Nasopharyngeal carcinoma. Lancet (London, England). 2016; 387: 1012-24.

2. Zhang L, Xiang J, Li G. The uncertain role of unmodified mesenchymal stem cells in tumor progression: what master switch? Stem cell research \& therapy. 2013; 4: 22.

3. Yang X, Hou J, Han Z, Wang Y, Hao C, Wei L, et al. One cell, multiple roles: contribution of mesenchymal stem cells to tumor development in tumor microenvironment. Cell \& bioscience. 2013; 3: 5 .

4. Shukrun R, Pode Shakked N, Dekel B. Targeted therapy aimed at cancer stem cells: Wilms' tumor as an example. Pediatric nephrology. 2014; 29: 815-23; quiz 21.

5. Schiffer D, Annovazzi L, Mellai M. A comprehensive view of tumor stem cells and their regulation by the microenvironment in glioblastoma. Neurological sciences : official journal of the Italian Neurological Society and of the Italian Society of Clinical Neurophysiology. 2016.

6. Peng S, Wu C, Sun W, Liu D, Luo M, Su B, et al. Snail-mediated cancer stem cell-like phenotype in human CNE2 nasopharyngeal carcinoma cell. Head \& neck. 2018; 40: 485-97.

7. Wei P, Niu M, Pan S, Zhou Y, Shuai C, Wang J, et al. Cancer stem-like cell: a novel target for nasopharyngeal carcinoma therapy. Stem cell research \& therapy. 2014; 5: 44.

8. Wang $Y$, Yin $\mathrm{W}$, Zhu $\mathrm{X}$. Blocked autophagy enhances radiosensitivity of nasopharyngeal carcinoma cell line CNE-2 in vitro. Acta oto-laryngologica. 2014; 134: 105-10.

9. Zhao K, Gong W, Zhu BS, Wu YY, Yang XD, Wu Y, et al. [Effects of damage-regulated autophagy modulator on the radiosensitivity of SGC7901 cell xenografts in nude mice]. Zhonghua wei chang wai ke za zhi $=$ Chinese journal of gastrointestinal surgery. 2011; 14: 892-5.

10. Maycotte P, Jones KL, Goodall ML, Thorburn J, Thorburn A. Autophagy Supports Breast Cancer Stem Cell Maintenance by Regulating IL6 Secretion. Molecular cancer research : MCR. 2015; 13: 651-8.

11. Xu F, Li X, Yan L, Yuan N, Fang Y, Cao Y, et al. Autophagy Promotes the Repair of Radiation-Induced DNA Damage in Bone Marrow Hematopoietic Cells via Enhanced STAT3 Signaling. Radiation research. 2017; 187: 382-96.

12. Gomes LR, Menck CFM, Leandro GS. Autophagy Roles in the Modulation of DNA Repair Pathways. International journal of molecular sciences. 2017; 18. 
13. Chaachouay $\mathrm{H}$, Fehrenbacher $\mathrm{B}$, Toulany $\mathrm{M}$, Schaller $\mathrm{M}$, Multhoff $\mathrm{G}$, Rodemann HP. AMPK-independent autophagy promotes radioresistance of human tumor cells under clinical relevant hypoxia in vitro. Radiotherapy and oncology : journal of the European Society for Therapeutic Radiology and Oncology. 2015; 116: 409-16.

14. Xu L, Wang Y, Liu Q, Luo H, Zhong X, Li Y. [Role of Autophagy in the Radiosensitivity of Human Lung Adenocarcinoma A549 Cells]. Zhongguo fei ai za zhi $=$ Chinese journal of lung cancer. 2016; 19: 799-804.

15. Chen D, Cui QC, Yang H, Barrea RA, Sarkar FH, Sheng S, et al. Clioquinol, a therapeutic agent for Alzheimer's disease, has proteasome-inhibitory, androgen receptor-suppressing, apoptosis-inducing, and antitumor activities in human prostate cancer cells and xenografts. Cancer research. 2007; 67: 1636-44.

16. Zheng J, Zhang $\mathrm{XX}, \mathrm{Yu} \mathrm{H}$, Taggart JE, Ding WQ. Zinc at cytotoxic concentrations affects posttranscriptional events of gene expression in cancer cells. Cellular physiology and biochemistry : international journal of experimental cellular physiology, biochemistry, and pharmacology. 2012; 29: $181-8$

17. Zheng J, Benbrook DM, Yu H, Ding WQ. Clioquinol suppresses cyclin D1 gene expression through transcriptional and post-transcriptional mechanisms. Anticancer Res. 2011; 31: 2739-47.

18. Yu H, Zhou Y, Lind SE, Ding WQ. Clioquinol targets zinc to lysosomes in human cancer cells. The Biochemical journal. 2009; 417: 133-9.

19. Yu H, Lou JR, Ding WQ. Clioquinol independently targets NF-kappaB and lysosome pathways in human cancer cells. Anticancer research. 2010; 30: 2087-92

20. Dawson LA, Anzai Y, Marsh L, Martel MK, Paulino A, Ship JA, et al. Patterns of local-regional recurrence following parotid-sparing conformal and segmental intensity-modulated radiotherapy for head and neck cancer. Int J Radiat Oncol Biol Phys. 2000; 46: 1117-26.

21. Ou C, Zhao Y, Feng G, Chen C, Tao Y, Zhou S, et al. RPA3 is a potential marker of prognosis and radioresistance for nasopharyngeal carcinoma. Journal of cellular and molecular medicine. 2017; 21: 2872-83.

22. Wang J, Guo LP, Chen LZ, Zeng YX, Lu SH. Identification of cancer stem cell-like side population cells in human nasopharyngeal carcinoma cell line. Cancer research. 2007; 67: 3716-24.

23. Lu S, Ke Y, Wu C, Zhong Y, Xie C, Zhou Y, et al. Radiosensitization of clioquinol and zinc in human cancer cell lines. BMC cancer. 2018; 18: 448.

24. Wang WJ, Wu SP, Liu JB, Shi YS, Huang X, Zhang QB, et al. MYC regulation of CHK1 and CHK2 promotes radioresistance in a stem cell-like population of nasopharyngeal carcinoma cells. Cancer research. 2013; 73: 1219-31.

25. Yang Y, Guo L, Yang F, Huang Q, Zhang F, Ma H, et al. Implication of tumor stem-like cells in the tumorigenesis of sporadic paraganglioma. Medical oncology. 2013; 30: 659 .

26. Su J, Xu XH, Huang $\mathrm{O}, \mathrm{Lu} \mathrm{MQ}$ Li DJ, Xue F, et al. Identification of cancer stem-like CD44+ cells in human nasopharyngeal carcinoma cell line. Archives of medical research. 2011; 42: 15-21.

27. Janisiewicz AM, Shin JH, Murillo-Sauca O, Kwok S, Le OT, Kong C, et al. CD44(+) cells have cancer stem cell-like properties in nasopharyngeal carcinoma. International forum of allergy \& rhinology. 2012; 2: 465-70.

28. Tu Z, Xu B, Qu C, Tao Y, Chen C, Hua W, et al. BRCC3 acts as a prognostic marker in nasopharyngeal carcinoma patients treated with radiotherapy and mediates radiation resistance in vitro. Radiation oncology (London, England). 2015; 10: 123.

29. Noguchi K, Konno M, Nishida N, Kawamoto K, Koseki J, Eguchi H, et al. [Therapeutic Implication Targeting for Cancer Stem Cells]. Gan to kagaku ryoho Cancer \& chemotherapy. 2015; 42: 1036-9.

30. Cai Z, Cao Y, Luo Y, Hu H, Ling H. Signalling mechanism(s) of epithelial-mesenchymal transition and cancer stem cells in tumour therapeutic resistance. Clin Chim Acta. 2018; 483: 156-63.

31. Chang L, Graham PH, Hao J, Ni J, Bucci J, Cozzi PJ, et al. PI3K/Akt/mTOR pathway inhibitors enhance radiosensitivity in radioresistant prostate cancer cells through inducing apoptosis, reducing autophagy, suppressing NHEJ and HR repair pathways. Cell death \& disease. 2014; 5: e1437.

32. Lin CI, Whang EE, Donner DB, Du J, Lorch J, He F, et al. Autophagy induction with RAD001 enhances chemosensitivity and radiosensitivity through Met inhibition in papillary thyroid cancer. Molecular cancer research : MCR. 2010; 8: $1217-26$.

33. Nam HY, Han MW, Chang HW, Kim SY, Kim SW. Prolonged autophagy by MTOR inhibitor leads radioresistant cancer cells into senescence. Autophagy. 2013; 9: 1631-2.

34. Magne N, Toillon RA, Bottero V, Didelot C, Houtte PV, Gerard JP, et al. NF-kappaB modulation and ionizing radiation: mechanisms and future directions for cancer treatment. Cancer letters. 2006; 231: 158-68.

35. Mendonca MS, Turchan WT, Alpuche ME, Watson CN, Estabrook NC, Chin-Sinex $\mathrm{H}$, et al. DMAPT inhibits NF-kappaB activity and increases sensitivity of prostate cancer cells to X-rays in vitro and in tumor xenografts in vivo. Free radical biology \& medicine. 2017; 112: 318-26.

36. Lan $F$, Yue $X$, Ren $G$, Li H, Ping L, Wang $Y$, et al, miR-15a/16 enhances radiation sensitivity of non-small cell lung cancer cells by targeting the TLR1/NF-kappaB signaling pathway. International journal of radiation oncology, biology, physics. 2015; 91: 73-81.

37. Ji K, Sun X, Liu Y, Du L, Wang Y, He N, et al. Regulation of Apoptosis and Radiation Sensitization in Lung Cancer Cells via the Sirt1/NF-kappaB/Smac Pathway. Cellular physiology and biochemistry : international journal of experimental cellular physiology, biochemistry, and pharmacology. 2018; 48: 304-16.

38. $\mathrm{Yu} \mathrm{H}$. Typical cell signaling response to ionizing radiation: DNA damage and extranuclear damage. Chin J Cancer Res. 2012; 24: 83-9.

39. Ding M, Zhang E, He R, Wang X. Newly developed strategies for improving sensitivity to radiation by targeting signal pathways in cancer therapy. Cancer science. 2013; 104: 1401-10.

40. Bulat T, Keta O, Koricanac L, Zakula J, Petrovic I, Ristic-Fira A, et al. Radiation dose determines the method for quantification of DNA double strand breaks. Anais da Academia Brasileira de Ciencias. 2016; 88: 127-36.

41. Turinetto V, Giachino C. Multiple facets of histone variant H2AX: a DNA double-strand-break marker with several biological functions. Nucleic acids research. 2015; 43: 2489-98.

42. Liu X, Li P, Hirayama $R, N i u$ Y, Liu X, Chen $W$, et al Genistein sensitizes glioblastoma cells to carbon ions via inhibiting DNA-PKcs phosphorylation and subsequently repressing NHEJ and delaying HR repair pathways. Radiotherapy and oncology : journal of the European Society for Therapeutic Radiology and Oncology. 2018.

43. Luo WR, Gao F, Li SY, Yao KT. Tumour budding and the expression of cancer stem cell marker aldehyde dehydrogenase 1 in nasopharyngeal carcinoma. Histopathology. 2012; 61: 1072-81.

44. Rahmanian N, Hosseinimehr SJ, Khalaj A. The paradox role of caspase cascade in ionizing radiation therapy. Journal of biomedical science. 2016; 23: 88.

45. Balcer-Kubiczek EK. Apoptosis in radiation therapy: a double-edged sword. Experimental oncology. 2012; 34: 277-85.

46. Koukourakis MI, Giatromanolaki A, Tsakmaki V, Danielidis V, Sivridis E. Cancer stem cell phenotype relates to radio-chemotherapy outcome in locally advanced squamous cell head-neck cancer. British journal of cancer. 2012; 106: 846-53.

47. Ouyang L, Shi Z, Zhao S, Wang FT, Zhou TT, Liu B, et al. Programmed cell death pathways in cancer: a review of apoptosis, autophagy and programmed necrosis. Cell proliferation. 2012; 45: 487-98.

48. Li H, Wang B, Zhang H, Katsube T, Xie Y, Gan L. Apoptosis Induction by Iron Radiation via Inhibition of Autophagy in Trp53(+/-) Mouse Testes: Is Chronic Restraint-Induced Stress a Modifying Factor? International journal of biological sciences. 2018; 14: 1109-21.

49. Kim KW, Hwang M, Moretti L, Jaboin JJ, Cha YI, Lu B. Autophagy upregulation by inhibitors of caspase- 3 and mTOR enhances radiotherapy in a mouse model of lung cancer. Autophagy. 2008; 4: 659-68. 